\title{
Conjugated linoleic acid decreased serum triacyloglycerol and changed fatty acid composition in rat's liver
}

\author{
R.B. Kostogrys ${ }^{1}$ and P.M. Pisulewski \\ Agricultural University of Kraków, Department of Human Nutrition, Faculty of Food Technology \\ Balicka 122, 30-149 Kraków, Poland
}

(Received 26 August 2009; revised version 28 April 2010; accepted 19 August 2010)

\begin{abstract}
Extensive research have indicated that commercial conjugated linoleic acid (CLA), fed to laboratory animals, showed several health-related properties. The objective of this study was to assess the effect of CLA on scrum lipid profile, plasma malondialdehyde and liver fatty acids profile in Wistar rats fed for $23 \mathrm{~d}$. The experimental diets were: I-AIN-93G - control (C), II- AIN-93G diet $+1.0 \%$ CLA. The CLA oil contained $600 \mathrm{~g} \mathrm{CLA} / \mathrm{kg}$, with equal representation of cis-9,trans-11 and trans-10,cis-12 CLA isomers. The experimental treatments had no effect on rats body weight, total cholesterol, HDL, LDL+VLDL and malondialdehyde. The triacylglycerol (TG) was significantly decreased after CLA supplementation. Liver weight, fat and histology were unchanged in CLA group. Liver cholesterol was insignificantly decreased in CLA diet. Dietary treatments had significant effects of on proportions of SFA and MUFA and PUFA in liver. In conclusion, CLA decreases serum TG. Additionally, liver fat composition were changed after CLA supplementation
\end{abstract}

KEY WORDS: rats, liver, CLA, lipid profile

\section{INTRODUCTION}

Conjugated linoleic acid (CLA) is a collective term to describe a class of positional and geometric isomers of linoleic acid (cis-9, cis-12, C18:2n-6) in which the two double bonds are separated by a single $\mathrm{C}-\mathrm{C}$ bond, but not by a

\footnotetext{
'Corresponding author: e-mail: rkostogrys@ar.krakow.pl
} 
methylene group $\left(-\mathrm{CH}_{2}-\right)$. CLA isomers are intermediate products of bacterial biohydrogenation of dietary unsaturated fatty acids in the rumen, and are mainly found in fat of ruminant milk and meat (Griinari and Bauman, 1999).

In the last ten years, extensive research have indicated that commercial CLA preparations fed to laboratory animals showed several health-related properties, including anti-adipogenic (Evans et al., 2002; Wang and Jones, 2004), anticarcinogenic (Belury, 2002; Field and Schley 2004), anti-inflammatory (O'Shea et al., 2004) and anti-atherogenic (Kritchevsky et al., 2002; Arbones-Mainar et al., 2006; Toomey et al., 2006; Franczyk-Żarów et al., 2008) effects. Additionally, positive health effects attributed to CLA isomers, particularly cis-9, trans-11CLA (c9t11CLA) in living organisms related to protection against oxidative stress (Czauderna et al., 2004; 2009; Korniluk et al., 2006).

The objective of this study was to assess the effect of a CLA diet $(1 \%)$ on serum lipid profile and liver in Wistar rats. Because the impact of dietary CLA on liver is controversial due to differences in species, isomer responses and degree and sensitivity to changes in adiposity, additionally, the effect of dietary CLA on hepatic steatosis was studied.

\section{MATERIAL AND METHODS}

\section{Animals, housing and feeding}

All experimental procedures complied with the Polish Ethical Standards. Twelve male albino rats (Wistar strain), weighing on average $120 \mathrm{~g}$, were obtained from the Institute of Animal Production in Kraków. The rats were housed in colony cages in a temperature-controlled environment $\left(22-25^{\circ} \mathrm{C}\right)$ with a 12 -h light cycle. They had free access to feed and water. The animals were randomly assigned to two experimental groups $(n=6)$ and fed semi-purified AIN-93G-based diets (Reeves, 1993), for the next $23 \mathrm{~d}$. The experimental diets were: I-AIN-93G - control (C), II- AIN-93G diet $+1.0 \%$ conjugated linoleic acid (Luta-CLA 60) (CLA) (Table 1). The CLA oil (Luta-CLA ${ }^{60}$ ), obtained from BASF (Ludwigshafen, Germany) contained $600 \mathrm{~g} \mathrm{CLA} / \mathrm{kg}$, with equal representation of two major CLA isomers (cis-9, trans-11 and trans-10, cis-12). Because of a dose-dependent effect of CLA isomer mixture (cis-9,trans-11, trans-10, cis-12) on animal models was demonstrated, in line with studies $1 \%$ of CLA were used. The body mass of rats was monitored weekly. 
Blood sampling and liver examination

At the end of the experiment, the rats were anaesthetized with thiopental (Biochemie $\mathrm{GmbH}$, Austria; $25 \mathrm{mg} / 100 \mathrm{~g}$ body mass). Blood samples were collected from the left ventricle of the heart into test tubes without anticoagulant or into heparinized tubes, centrifuged $(1500 \mathrm{~g}, 15 \mathrm{~min})$ to obtain serum samples or plasma, respectively. The samples were frozen $\left(-80^{\circ} \mathrm{C}\right)$ and stored for analyses. Livers were dissected and weighted. A part of liver were removed and fixed in $4 \%$ buffered formalin for histological examination (Kiernan, 1990). Liver samples were frozen $\left(-80^{\circ} \mathrm{C}\right)$ for assessment of the total cholesterol and fatty acid profile (GCMS).

Table 1. Composition of experimental diet, $\%$

\begin{tabular}{lll}
\hline Item & C & CLA \\
\hline Maize starch & 53.2486 & 53.2486 \\
Caseine & 20 & 20 \\
Sucrose & 10 & 10 \\
Soyabean oil & 7 & 5.333 \\
Celulose powder & 5 & 5 \\
Mincral mixture & 3.5 & 3.5 \\
Witamin mixture & 1 & 1 \\
Choline & 0.25 & 0.25 \\
Tert-butylhydrochinon & 0.0014 & 0.0014 \\
CLA $^{3}$ & - & 1.667 \\
\hline
\end{tabular}

${ }^{1}$ AIN-93G mineral mixture, ${ }^{2} \mathrm{AIN}-93 \mathrm{G}$ vitamin mixture, ${ }^{3} \mathrm{CLA}$ mix - the CLA oil (Luta-CLA ${ }^{*} 60$ ), obtained from BASF (Ludwigshafen, Germany) contained $600 \mathrm{~g} \mathrm{CLA} / \mathrm{kg}$, with equal representation of two major CLA isomers (cis-9, trans-11 and trans-10, cis-12)

Analyses

Serum samples were analysed using commercially available kits for: total cholesterol (TC; Liquick Cor-Chol 60 No 2-204; Cormay, Lublin, Poland), HDL-cholesterol (HDL; Olympus Diagnostica GmbH No OSR 6287; Hamburg, Germany) and triacylglycerols (TG; Liquick Cor-TG 30 No 2-262; Cormay, Lublin, Poland). The LDL+VLDL were calculated as the difference between TC and HDL. Malondialdehyde (MDA) was determined in plasma samples using the commercially available kit OXI-TEK TBARS (No 850-287-KI01). The fat from liver were extracted using LECO. Fatty acids composition in liver were analysed. Shortly, the samples $(20 \mathrm{mg})$ were placed in vials and treated with $2 \mathrm{ml}$ solution of $0.5 \mathrm{M} \mathrm{KOH}$ in methanol. The samples were heated at $60^{\circ} \mathrm{C}$ for $10 \mathrm{~min}$. Next, $2 \mathrm{ml}$ of $14 \% \mathrm{BF}_{3}$ in methanol was added and heated at $60^{\circ} \mathrm{C}$ for $10 \mathrm{~min}$. After cooling, $2 \mathrm{ml}$ of hexane and $2 \mathrm{ml}$ saturated sodium chloride was added. The mixture was vortexed. The upper $n$-hexane layer was transferred to eppendorf tubes 
and dried with anhydrous $\mathrm{Na}_{2} \mathrm{SO}_{4}$. The analysis of all FAME was performed on a SHIMADZU GC-MS- QP 5050A equipped with a SP-2560 capillary column $(100 \mathrm{~m} \times 0.25 \mathrm{~mm}$ i.d. $\times 0.25 \mu \mathrm{m}$ film thickness (Supelco). Helium was the carrier gas and operated at flow rate of $1.8 \mathrm{ml} / \mathrm{min}$. Injector temperature was maintained at $245^{\circ} \mathrm{C}$, detector temperature was $200^{\circ} \mathrm{C}$. The total FAME profile in a $1 \mu \mathrm{l}$ injection at a split mode was determined. The oven temperature was operated at $60^{\circ} \mathrm{C}$ for $5 \mathrm{~min}$, then the temperature programmed at $5^{\circ} \mathrm{C} / \mathrm{min}$ to $180^{\circ} \mathrm{C}$, held for $16 \mathrm{~min}$, programmed at $5^{\circ} \mathrm{C} / \mathrm{min}$ to $220^{\circ} \mathrm{C}$, held for $7 \mathrm{~min}$. FAME identification was validated and based on electron impact ionization mode.

A part of the liver was fixed in $4 \%$ buffered formalin ( $\mathrm{pH} 7.4$ ) for 3 days. Then the tissues was dehydrated in alcohol, embedded in paraffin and sectioned serially at $7 \mu \mathrm{m}$. For histological evaluation the sections were stained with haematoxylin and eosin (Kiernan, 1990).

\section{Statistical analysis}

The data was analysed by the STATISTICA version 6.1 package (StatSoft, Tulsa, OK). Treatment means were compared using the Fisher test and $\mathrm{P}$ values $<0.05$ were considered as showing a significant difference between treatment means.

\section{RESULTS}

Effect of CLA on body weight. The experimental diets had no significant effect on body weight of the rats (Figure 1).

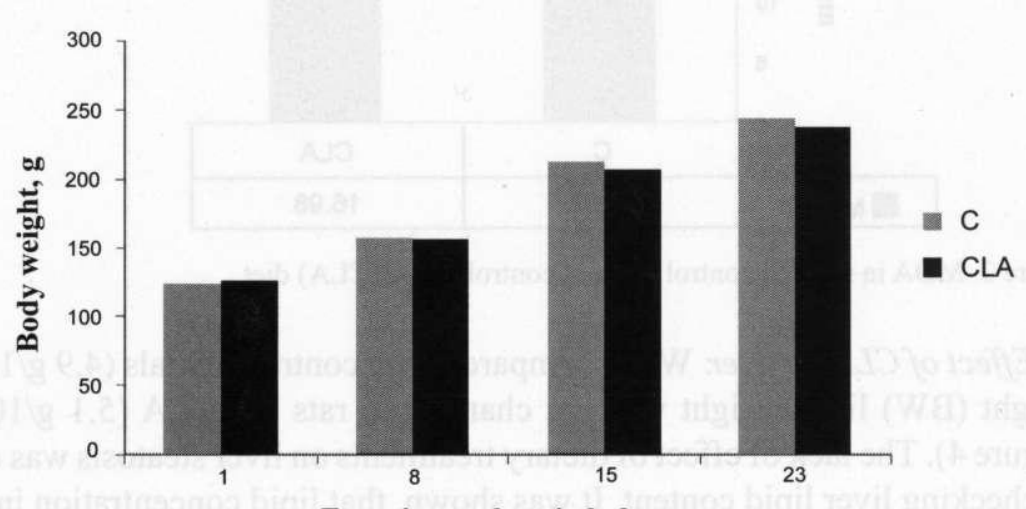

Experimental period, days

Figure 1. The growth of rats (g) fed control (C) and control+CLA (CLA) diet 
Effect of CLA on serum lipid profile. Dietary treatments had no significant effects on TC and HDL fraction. The TC and HDL tended to increase in blood serum of rats fed CLA, whereas LDL+VLDL were unchanged. The evident effect of dietary treatments was the decrease of serum TG in rats fed CLA as compared to control $(\mathrm{P}<0 \cdot 05)$ (Figure 2).

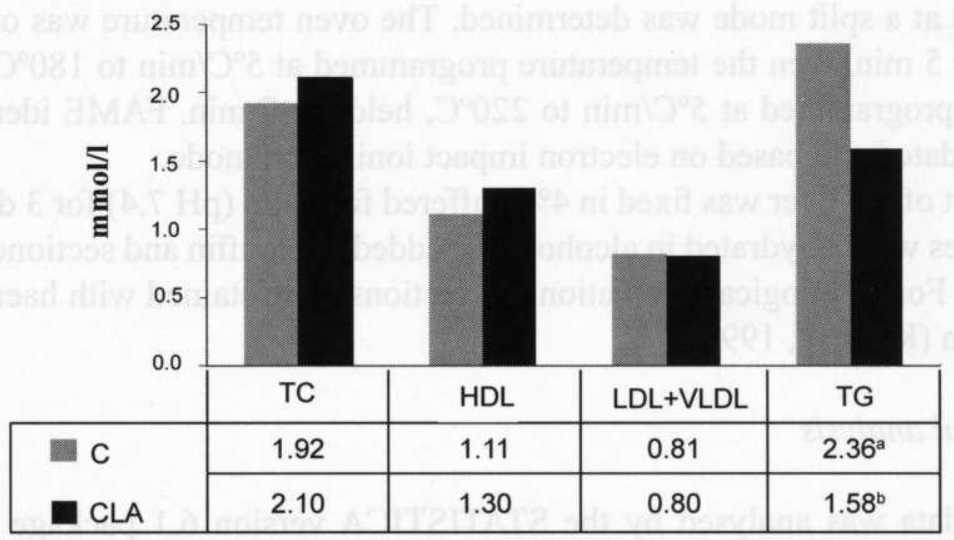

Figure 2. Total cholesterol (TC), HDL-choresterol (HDL), LDL+VLDL and triacylglicerol (TG) in serum rats fed: control (C) and control+CLA (CLA) diet. Data are means \pm SEM. The means bearing different letters were significantly different $(\mathrm{P}<0.05)$

Effect of CLA on MDA concentration. MDA concentrations were unchanged after dietary treatments $(17.98 \mathrm{vs} 16.09 \mathrm{nmol} / \mathrm{ml})$ (Figure 3$)$.

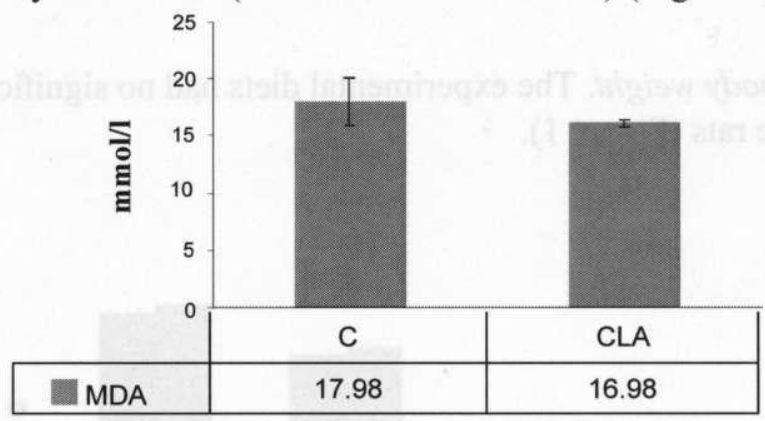

Figure 3. MDA in rats fed control (C) and control+CLA (CLA) diet

Effect of CLA on liver. When compared with control animals $(4.9 \mathrm{~g} / 100 \mathrm{~g}$ body weight (BW) liver weight was not changed in rats fed CLA $(5.1 \mathrm{~g} / 100 \mathrm{~g} \mathrm{BW})$ (Figure 4). The lack of effect of dietary treatments on liver steatosis was confirmed by checking liver lipid content. It was shown, that lipid concentration in liver was unchanged (4.27 vs $4.1 \%$ ) (Figure 5). Additionally, the rats fed CLA showed no morphological alterations in the liver. The histology confirmed no effect of dietary treatment on liver steatosis (Figure 6). 
KOSTOGRYS R.B.,PISULEWSKI P.M.

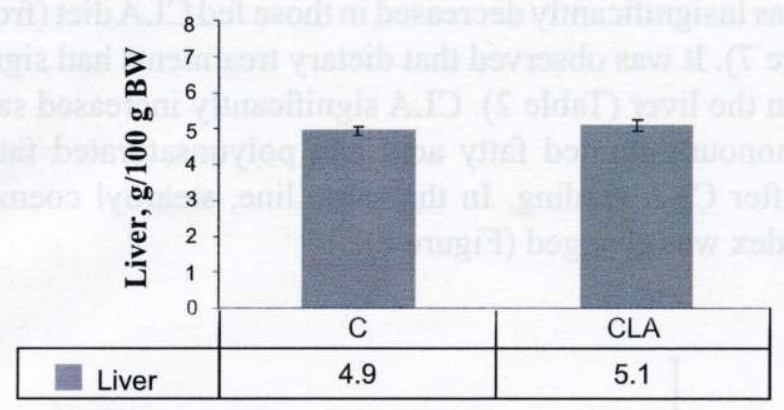

Figure 4. Liver weight in rats fed control (C) and control+CLA (CLA) diet

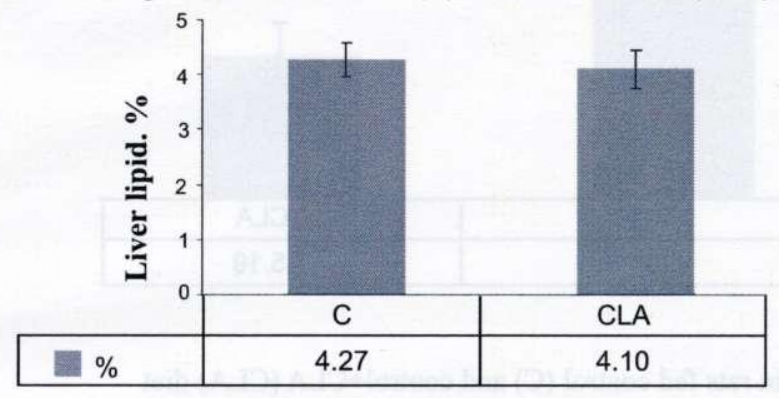

Figure 5. Lipid content in rats liver, \%
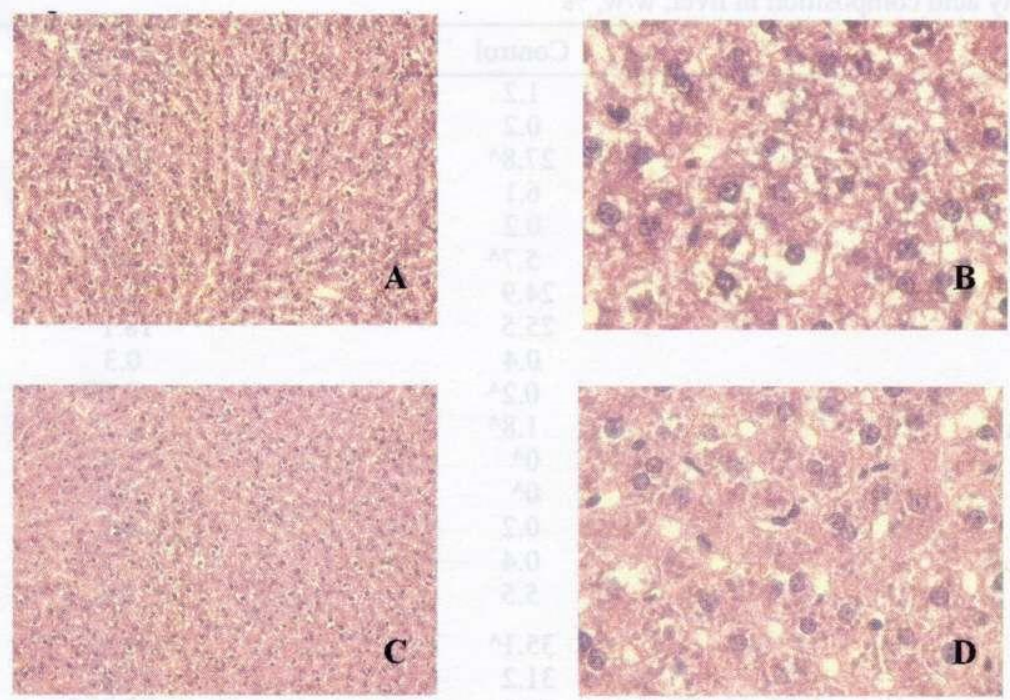

Figure 6. Liver histology in rats fed control $(A, B)$ and control+CLA (C,D) diet. Origin magnification $100 \times(A, C)$ and $400 \times(B, D)$ 
Liver cholesterol was insignificantly decreased in those fed CLA diet (from 9.02 to $5.19 \mathrm{mmol} / \mathrm{l}$ ) (Figure 7). It was observed that dietary treatments had significant effects on fatty acids in the liver (Table 2). CLA significantly increased saturated fatty acids whereas monounsaturated fatty acid and polyunsaturated fatty acid tended to decreased after CLA feeding. In the same line, stearoyl coenzyme A desaturase (SCD-1) index was changed (Figure 8).

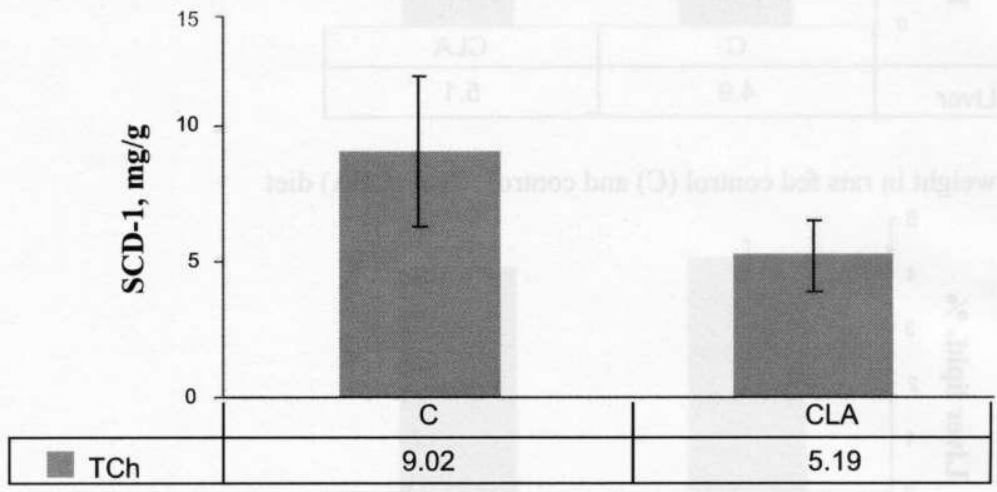

Figure 7. Liver cholesterol in rats fed control (C) and control+CLA (CLA) diet

Table 2. Fatty acid composition in liver, w/w, \%

\begin{tabular}{lcc}
\hline Item & Control & CLA \\
\hline C14:0 & 1.2 & 1.3 \\
C15:0 & 0.2 & 0.2 \\
C16:0 & $27.8^{\mathrm{A}}$ & $34.7^{\mathrm{B}}$ \\
C16:1 & 6.1 & $4.5^{\circ}$ \\
C17:0 & 0.2 & 0.2 \\
C18:0 & $5.7^{\mathrm{A}}$ & $8.9^{\mathrm{B}}$ \\
C18:1 n-9 & 24.9 & 22.8 \\
C18:2 n-6 & 25.5 & 18.1 \\
C18:3 n-6 & 0.4 & 0.3 \\
C20:1 & $0.2^{\mathrm{A}}$ & $0.1^{\mathrm{B}}$ \\
C18:3, ALA & $1.8^{\mathrm{A}}$ & $1.1^{\mathrm{B}}$ \\
c9 t11 & $0^{\mathrm{A}}$ & $1.4^{\mathrm{B}}$ \\
t10 c12 & $0^{\mathrm{A}}$ & $0.4^{\mathrm{B}}$ \\
C20:2 n-6 & 0.2 & 0.2 \\
C20:3, DGLA & 0.4 & 0.4 \\
C20:4 n-6 & 5.5 & 7.4 \\
SFA & $35.1^{\mathrm{A}}$ & $45.4^{\mathrm{B}}$ \\
MUFA & 31.2 & 27.4 \\
PUFA & 33.8 & 27.3 \\
MUFA:SFA & $0.9^{\mathrm{A}}$ & $0.6^{\mathrm{B}}$ \\
\hline
\end{tabular}



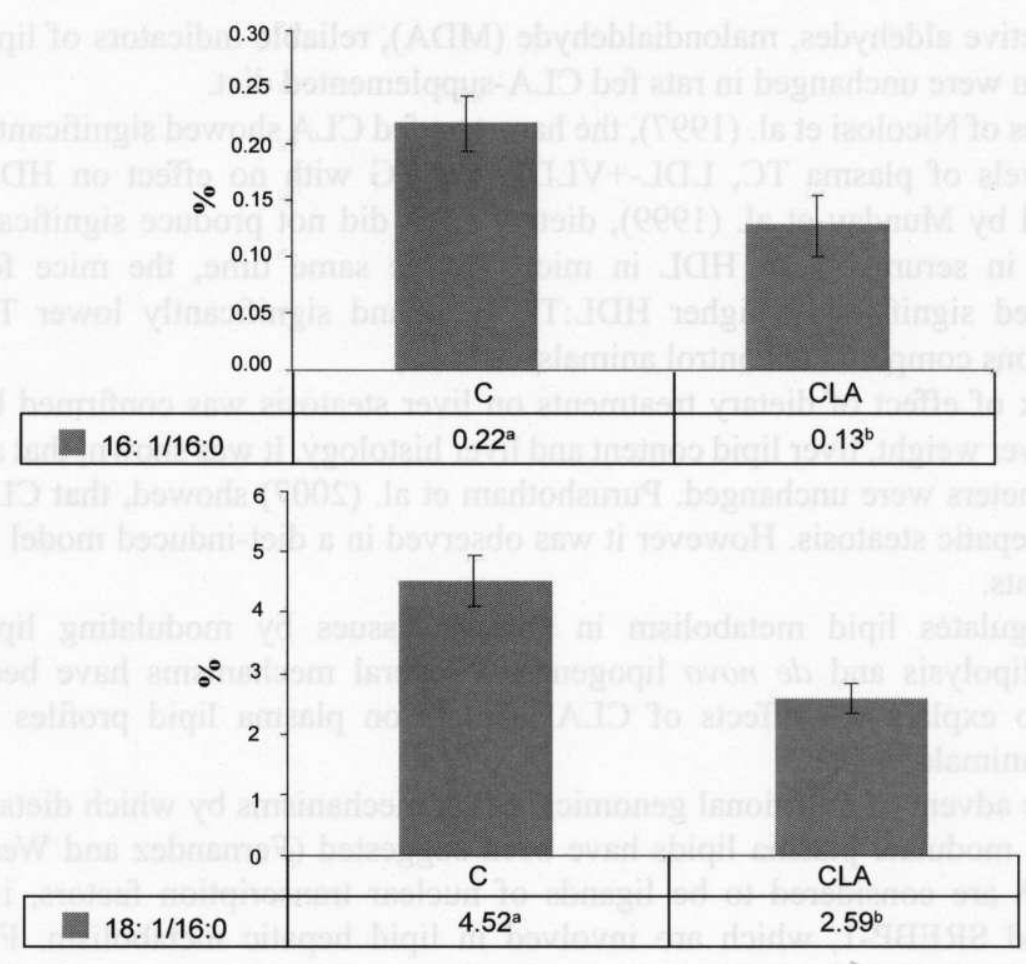

Figure 8. Hepatic stearoyl coenzyme A desaturase 1 index in rats fed control (C) and control+CLA (CLA) diet

\section{DISCUSSION}

The objective of this study was to assess the effect of CLA on serum lipid profile, plasma malondialdehyde and liver's lipids. Wistar rats model were chose to study the effect of CLA because of sensitive to hepatic steatosis. In our experiment mix of CLA (cis-9, trans-11, trans-10, cis-12; 50:50, 1\%) was used. In the present study, no effects of CLA on body weight of rats were evidenced. Additionally, CLA had no effect on liver weight and hepatic lipid accumulation. In line in our study, some authors (Korniluk et al., 2006; Purushotham et al., 2007) showed, that conjugated linoleic acid does not reduce body fat in rats.

Dietary treatments had no significant effects on TC, HDL and LDL+VLDL fraction. The evident effect of dietary treatments was the decrease of serum TG in rats fed CLA as compared to control $(\mathrm{P}<0.05)$. TG were significantly $(\mathrm{P}<0.05)$ decreased in animals fed CLA-supplemented diet. Liver cholesterol was insignificantly decreased in those fed CLA diet (from 9.2 to $5.15 \mathrm{mg} / \mathrm{g}$ tissue). 
The reactive aldehydes, malondialdehyde (MDA), reliable indicators of lipid peroxidation were unchanged in rats fed CLA-supplemented diet.

In studies of Nicolosi et al. (1997), the hamsters fed CLA showed significantly reduced levels of plasma TC, LDL-+VLDL and TG with no effect on HDL. As reported by Munday et al. (1999), dietary CLA did not produce significant differences in serum TC or HDL in mice. At the same time, the mice fed CLA showed significantly higher HDL:TC ratio and significantly lower TG concentrations compared to control animals.

The lack of effect of dietary treatments on liver steatosis was confirmed by checking liver weight, liver lipid content and liver histology. It was shown, that all these parameters were unchanged. Purushotham et al. (2007) showed, that CLA decreases hepatic steatosis. However it was observed in a diet-induced model of obesity in rats.

CLA regulates lipid metabolism in various tissues by modulating lipid oxidation, lipolysis and de novo lipogenesis. Several mechanisms have been proposed to explain the effects of CLA isomers on plasma lipid profiles in laboratory animals.

With the advent of nutritional genomics, novel mechanisms by which dietary CLA might modulate plasma lipids have been suggested (Fernandez and West, 2005). CLA are considered to be ligands of nuclear transcription factors, i.e. PPAR- $\alpha$ and SREBP-1, which are involved in lipid hepatic metabolism. For instance, activation of PPAR- $\alpha$ by CLA may lead to several effects, e.g., reduction of fatty acid and triacylglycerol synthesis and VLDL production. The SREBP-1 is a regulator of genes encoding enzymes involved in both lipogenesis and cholesterol biosynthesis, thus providing a mechanism by which CLA may decrease plasma cholesterol and TG levels.

In our study it was observed that dietary treatments had significant effects on proportions of fatty acids in liver. CLA significantly increased saturated fatty acid (C16:0, C18:0) when monounsaturated fatty acid (C20:1) had statistically decreased after CLA feeding. Additionally, CLA significantly decreased index of hepatic SCD-1 in rats compared to control animals. Our results are in accordance with other studies showing similar effects (Czauderna et al., 2004, 2009; Korniluk et al., 2006).

It was shown, that CLA can modulate lipid synthesis and accumulation by decreasing SCD-1 mRNA and activity. SCD- 1 catalyses the rate-limiting step in the cellular biosynthesis of monounsaturated fatty acid primarily oleate (18:1) and palmitoleate (16:1) from stearic (18:0) and palmitic (16:0) acid. These fatty acid (oleate and palmitoleate) can be incorporated into and stored as TG in the liver. Inhibition of SCD-1 is associated with increased $\beta$-oxidation as well.

CLA has been reported to be incorporated and to have a fate similar to other fatty acids in biological systems; supplementation increased tissue CLA levels 
incorporated into both triacylglyceride and phospholipid fractions (Korniluk et al., 2006).

It was shown that CLA in diet $(1.0 \%)$ led to increased concentrations of CLA in liver lipids. Although both CLA isomers were ingested at equivalent amounts, trans-10, cis-12 was incorporated in significantly lower proportion than cis-9, trans-11 into lipids. Moreover, cis-9, trans-11 CLA was incorporated into lipids more efficiently than trans-10, cis-12 CLA.

\section{CONCLUSIONS}

In conclusion, conjugated linoleic acid (CLA) fed at $1 \%$ level $(w / w)$ decreases serum triacylglicerols. Although CLA had no effect on liver steatosis, fatty acid composition in Wistar rat's liver were changed after dietary treatment. CLA significantly increased saturated fatty acids, whereas monounsaturated fatty acid and polyunsaturated fatty acid tended to decreased after CLA feeding. In the same line, SCD-1 index was changed.

\section{REFERENCES}

Arbonćs-Mainar J.M., Navarro M.A., Acín S., Guzmán M.A., Arnal C., Surra J.C., Carnicer R., Roche H.M., Osada J., 2006. Trans-10, cis-12- and cis-9, trans-11-conjugated linoleic acid isomers selectively modify HDL-apolipoprotein composition in apolipoprotein $\mathrm{E}$ knockout mice. J. Nutr. 136, 353-359

Belury M.A., 2002. Inhibition of carcinogenesis by conjugated linoleic acid: potential mechanisms of action. J. Nutr. 132, 2995-2998

Czauderna M., Kowalczyk J., Krajewska K.A., Rozbicka A.J., Michalski J.P., 2009. Dietary selenite and conjugated linoleic acid isomers influence fatty acid concentrations in the liver and femoral muscles of rats. J. Anim. Feed Sci. 18, 3, 564-581

Czauderna M., Kowalczyk J., Niedźwiedzka K.M., Wąsowska I., Pastuszewska B., Bulska E., Ruszczyńska A., 2004. Liver and body mass gain, content of conjugated linoleic acid (CLA) isomers and other fatty acids in the liver of rats fed CLA isomers and selenium. J. Anim. Feed Sci. 13, 353-369

Evans M., Brown J., McIntosh M., 2002. Isomer-specific effects of conjugated linoleic acid (CLA) on adiposity and lipid metabolism. J. Nutr. Biochem. 13, 508-516

Fernandez M.L., West K.L., 2005. Mechanisms by which dietary fatty acids modulate plasma lipids. J. Nutr. 135, 2075-2078

Field C.J., Schley P.D., 2004. Evidence for potential mechanisms for the effect of conjugated linoleic acid on tumor metabolism and immune function: lessons from n-3 fatty acids. Amer. J. Clin. Nutr. 79, I190S-1198S

Franczyk-Żarów M., Kostogrys R.B., Szymczyk B., Jawień J., Gajda M., Cichocki T., Wojnar L., Chłopicki S., Pisulewski P.M., 2008. Functional effects of eggs, naturally enriched with conjugated linoleic acid (CLA), on the blood lipid profile, development of atherosclerosis and composition of atherosclerotic plaque in apolipoprotein $\mathrm{E}$ and low density lipoprotein receptor double-knockout mice (apoE/LDLR -/-). Brit. J. Nutr. 99, 49-58 
Griinari J.M., Bauman D.E., 1999. Biosynthesis of conjugated linoleic acid and its incorporation into meat and milk in ruminants. In: M.P. Yurawecz, M.M. Mossoba, J.K.G. Kramer, M.W. Pariza, G.J. Nelson (Editors). Advances in Conjugated Linoleic Acid Research. AOCS Press. Champaign, IL, pp. 180-199

Kiernan J.A., 1990. Histological and Histochemical Methods. Theory and Practice. $2^{\text {nd }}$ Edition. Pergamon Press, Great Britain BPCC, Wheatons LTD. Exeter, pp. 413-421

Korniluk K., Czauderna M., Kowalczyk J., Mieczkowska A., Taciak M., Leng L., 2006. Influence of dietary conjugated linoleic acid isomers and selenium on growth, feed efficiency, and liver fatty acid profile in rats, J. Anim. Feed Sci. 15, 131-146

Kritchevsky D., Tepper S.A., Wright S., Czarnecki S.K., 2002. Influence of graded levels of conjugated linoleic acid (CLA) on experimental atherosclerosis in rabbits. Nutr. Res. 22, 12751279

Munday J.S., Thompson K.G., James K.A.C., 1999. Dietary conjugated linoleic acids promote fatty streak formation in the C57BL/6 mouse atherosclerosis model. Brit. J. Nutr. 81, 251-255

Nicolosi R.J., Rogers E.J., Kritchevsky D., Scimeca J.A., Huth P.J., 1997. Dietary conjugated linoleic acid reduces plasma lipoproteins and early atherosclerosis in hypercholesterolemic hamsters. Artery 22, 266-277

O'Shea M., Bassaganya-Riera J., Mohede I.C.M., 2004. Immunomodulatory properties of conjugated linoleic acid. Amer. J. Clin. Nutr. 79, 1199S-1206S

Purushotham A., Shrode G.E., Wendel A.A., Liu L.F., Belury M.A., 2007. Conjugated linoleic acid docs not reduce body fat but decreases hepatic steatosis in adult Wistar rats. J. Nutr. Biochem. $18,676-684$

Reeves P.G., Nielsen F.H., Fahey G.C., 1993. AIN-93 purified diets for laboratory rodents: Final report of the American Institute of Nutrition ad hoc Writing Committee on the reformulation of the AIN-76A rodent diet. J. Nutr. 123, 1939-1951

Toomey S., Harhen B., Roche H.M., Fitzgerald D., Belton O., 2006. Profound resolution of early atherosclerosis with conjugated linoleic acid. Atherosclerosis 187, 40-49

Wang Y., Jones P.J.H., 2004. The role of conjugated linoleic acid in human health. Dietary conjugated linoleic acid and body composition. Amer. J. Clin. Nutr. 79, 1153S-1158S 